\title{
СТАНДАРТИЗАЦИЯ МЕТОДИКИ ИЗМЕРЕНИЯ КАРЬЕРНОГО САМООПРЕДЕЛЕНИЯ
}

\author{
Андрей Н. Дёмин*, Артём Б. Седых, Борис Р. Седых
}

Кубанский государственный университет, г. Краснодар, Российская Федерация

*E-mail:demin@manag.kubsu.ru

Исследование выполнено при финансовой поддержке РГНФ в рамках научно-исследовательского проекта РГНФ № 13-36-01037

Введение. В статье представлены результаты заключительного этаna aдаnтации методики Д. Холланда, Д. Дайжера, П. Пауэра «My Vocational Situation» (MVS), нашедшей широкое применение в мировой психологической науке и практике. Методика предназначена для определения проблем в трех областях: 1) профессиональная идентичность; 2) барьеры в принятии карьерных решений; 3) информированность о возможностях трудоустройства и обучения. Русскоязычный вариант, получивший название «Методика измерения карьерного самоопределения» (МИКС), расширяет уже существующие в отечественной психологии способы оченки профессиональной идентичности и является хорошим дополнением других инструментов и подходов к психологическому измерению карьерных процессов.

Методы. "Методика измерения карьерного самоопределения» включает шкалы «Профессиональная идентичность», "Барьеры развития», «Потребность в информации». В двух последних шкалах увеличено количество пунктов по сравнению с англоязычным вариантом. Приводятся показатели внутренней и ретестовой надежности шкал, их конструктной и прогностической валидности. С учетом распределения сырых данных, собранных на российских выборках студентов выпускного курса бакалавриата и выпускников бакалавриата, имеющих 2-х-4-х летний опыт работы, шкалы были подвергнуты прочедуре нелинейной стандартизации.

Результаты. Выделены уровни сформированности профессиональной идентичности и самооценки барьеров карьерного развития в стенах Кеттелла (объединенные выборки студентов выпускного курса бакалавриата и выпускников бакалавриата, $n=720)$, уровни потребности в информации в z-оценках для студентов выпускного курса $(n=363)$ и выпускников бакалавриата ( $n=357)$. В статью включены текст методики и прочедура подсчета сырых баллов. 
Обсуждение результатов. Завершена русскоязычная адаптация методики «My Vocational Situation», включая ее стандартизачию. Получены новые психометрические результаты. Они дают основание использовать методику в отечественных научных исследованиях и консультативной практике, в том числе в мониторинговых и сравнительных исследованиях.

Ключевые слова: теория Холланда, карьера, карьерное самоопределение, выпускники вуза, профессиональная идентичность, барьеры развития, потребность в информачии, психодиагностическая методика, стандартизачия

\title{
Основные положения:
}

> завершена адаптачия методики Д. Холланда, Д. Дайжера, П. Пауэра «Му Vocational Situation» (русскоязычный вариант - «Методика измерения карьерного самоопределения») на российских выборках студентов и выпускников бакалавриата;

> приводятся текст методики, прочедура подсчета сырых баллов, результаты стандартизации методики.

Для цитирования: Дёмин А. Н., Седых А. Б., Седых Б. Р. Стандартизация методики измерения карьерного самоопределения // Российский психологический журнал. - 2017. - Т. 14, № 2. - С. 151-170.

Материалы статьи получены 08.11.2016

UDC 159.9.072

DOI: 10.21702/rpj.2017.2.9

\section{STANDARDIZATION OF THE TECHNIQUE FOR MEASURING CAREER SELF-DETERMINATION}

\author{
Andrey N. Diomin*, Artem B. Sedykh, Boris R. Sedykh
}

Kuban State University, Krasnodar, Russian Federation

*Correspondence author. E-mail: demin@manag.kubsu.ru

\section{Acknowledgments}

This study was supported by the Russian Humanitarian Science Foundation, project no. 13-36-01037

Introduction. The My Vocational Situation (MVS) scale by John L. Holland, Denise Daiger, and Paul G. Power is widely used in the world psychological theory and practice. The article presents the results of the final stage of its modification. This 


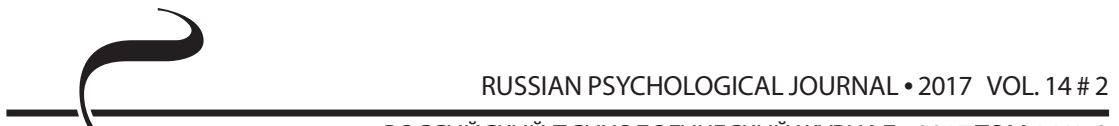

РОССИЙСКИЙ ПСИХОЛОГИЧЕСКИЙ ЖУРНАЛ • 2017 ТОМ 14 № 2

scale reveals problems in the following three areas: (a) vocational identity; (b) barriers in making career decisions; (c) information about employment opportunities and training. The Russian version, called The Technique for Measuring Career SelfDetermination (TMCS), expands the ways of assessing professional identity that already exist in Russian psychology. This technique is a good supplement to other tools and approaches to psychological measuring career processes.

Methods. The Technique for Measuring Career Self-Determination includes the following scales: (a) Vocational Identity; (b) Barriers; (c) Occupational Information. The last two scales have more items in comparison with the English version. The study shows rates of internal reliability, test-retest reliability, their construct and predictive validity. The scales were subject to non-linear standardization, taking into account the distribution of raw scores in samples of Russian final-year bachelor students and bachelor graduates with 2-4 years' experience.

Results. The study revealed the levels of vocational identity and self-assessment of barriers in Cattell's sten scores (united samples of the final-year bachelor students and bachelor graduates, $n=720$ ), the levels of occupational information in the $z$-scores for the final-year bachelor students $(n=363)$ and bachelor graduates $(n=357)$. The article includes the text of the technique and the calculation of raw scores.

Discussion. The Russian modification of The My Vocational Situation (MVS) scale and its standardization have been accomplished. The study presents new psychometric results. The findings suggest that the technique is applicable to domestic research and consulting practice, including the monitoring and comparative studies.

Keywords: Holland's theory, career, career self-determination, university graduates, vocational identity, barriers, occupational information, psychodiagnostic technique, standardization

\section{Highlights}

> The modification of The My Vocational Situation (MVS) scale by John L. Holland, Denise Daiger, and Paul G. Power (Russian version - The Technique for Measuring Career Self-Determination) in the sample of Russian bachelor students and graduates has been accomplished.

> The study presents the text of the technique, the calculation of raw scores, and standardization results.

For citation: Diomin A. N., Sedykh A. B., Sedykh B. R. Standardization of the technique for measuring career self-determination. Rossiiskii psikhologicheskii zhurnal - Russian Psychological Journal, 2017, V. 14, no. 2, pp. 151-170 (in Russian).

Original manuscript received 08.11.2016 


\section{Введение}

Традиционно исследуются не только отдельные психологические составляющие карьеры (интересы, притязания, принятие карьерных решений, установки на мобильность и др.), но также их комплексы, наделяемые авторами соответствующих концепций/подходов важной ролью в формировании карьеры. Например, Д. Сьюпер с последователями, оперируя понятием «карьерная адаптивность», предлагал эффективный, но достаточно громоздкий аппарат диагностики факторов карьерного развития в переходные моменты жизни (отношение к труду как к ценности; способность управлять собственной жизнью; рефлексивные умения, предполагающие научение из собственного опыта; наличие планов и перспектив в области карьеры; информированность о мире труда и профессий; особенности принятия решений; способность исследовать варианты развития) (см.: [1, 2, 3, 4]).

Способность находить и реализовывать возможности для желательного развития карьеры нашла отражение в понятии «способность к занятости». Это согласованная комбинация карьерной идентичности, личностной адаптивности, социального и человеческого капитала (имеются в виду социальная сеть личности, образование и профессиональный опыт) [5].

В рамках ресурсного подхода используется понятие «карьерный капитал». Это один из вариантов человеческого капитала, включающий три вида знания, важных для карьеры: «знания-как» обеспечивают навыками и способностями понимания того, что требуется для достижения высокой производительности и продуктивности; «знания-зачем» дает энергию, чувство цели, мотивацию и идентификацию с работой; «знания-кто» отсылают к внешним и внутриорганизационным профессиональным и социальным связям, т. е. к тому, что можно назвать социальной сетью личности $[6,7]$.

Г. Готтфредсон - ближайший последователь Д. Холланда - предлагал диагностировать конгруэнтность личности и профессиональной среды, уровень профессиональной идентичности, склонность к риску: их соотношение позволяет предсказывать принятие карьерных решений и варианты карьерного развития работника. Высказывалось предположение о том, что неконгруэнтные личности (т. е. имеющие несоответствие между своим типом личности и типом профессиональной среды) с высокой профессиональной идентичностью, склонностью к риску будут пытаться покинуть текущую профессиональную среду или изменить ее. Напротив, конгруэнтные личности, а также люди с низкой профессиональной идентичностью и склонностью избегать риска будут демонстрировать стабильность [1, 8].

Еще один пример комплексной оценки карьеры, предложенный в школе Д. Холланда, - разработка методики MVS (My Vocational Situation) [9], предназначенной для определения проблем в трех областях: 1) профессиональная 
идентичность; 2) барьеры в принятии карьерных решений; 3) информированность о возможностях трудоустройства и обучения [10]. Методика используется для изучения начальных этапов карьеры, она нашла широкое применение не только в США, но также в европейских и некоторых азиатских странах (соответствующие версии MVS появились совсем недавно). Методика сыграла важную роль для включения профессиональной идентичности в регулярно обновлявшуюся теорию Д. Холланда [11].

Нами осуществлена русскоязычная адаптация данной методики, название - «Методика измерения карьерного самоопределения» (МИКС). Цель cmamьu: представить результаты заключительного этапа адаптации методики, включающего ее стандартизацию.

Полагаем, что методика не только расширит линейку уже существующих в отечественной психологии способов оценки профессиональной идентичности, реализующих альтернативный подход Э. Эриксона - Д. Марсии [12, 13], но и станет хорошим дополнением других инструментов и подходов к психологическому измерению карьерных процессов [14, 15, 16, 17 и др.].

\section{Методы}

Согласно Д. Холланду, профессиональная идентичность относится к ясности и стабильности целей и самовосприятия человека в области карьеры $[18,19]$; она сигнализирует об уровне трудностей в принятии карьерных решений и уверенности человека в своей способности принимать правильные решения в ситуациях неопределенности [18]. Шкала изначально коррелировала с такими субъективными составляющими карьеры, как определенность профессионального выбора, удовлетворенность профессиональным выбором, межличностная компетентность и нерешительность. Результаты исследований, выполненных на разных выборках, в том числе людей, испытывающих трудности в сфере обучения и трудовой занятости, свидетельствуют о том, что профессиональная идентичность измеряет не только трудности в принятии карьерных решений; в известном смысле она выступает индикатором психологического здоровья и психологического благополучия личности и поэтому может выступать инструментом их измерения [20]. Русскоязычная версия шкалы содержит 18 пунктов (как в оригинальной версии).

Оригинальная версия шкалы барьеров включает 4 утверждения, с помощью которых оценивается восприятие внешних и личностных барьеров становления карьеры. В нашем варианте количество пунктов увеличено до 7, т. к. дополнительно учитывались: уровень готовности к принятию решений, фактор социальных связей и фактор текущей социально-экономической ситуации в построении карьеры. В состав МИКС данная шкала включена под названием «Барьеры развития». 
Третья шкала (оценка нехватки информации, обучения) в оригинальном варианте включает 4 пункта. В русскоязычном варианте добавлен еще один пункт. В состав МИКС данная шкала включена под названием «Потребность в информации».

Согласно уже опубликованным результатам [10], значения коэффициента á Кронбаха достаточно высокие («Профессиональная идентичность» 0.857, «Барьеры развития» - 0.758, «Потребность в информации» - 0.801) и свидетельствуют о внутренней надежности всех трех шкал МИКС; они сопоставимы с опубликованными показателями испанской, португальской, латвийской версий методики [21, 22, 23].

В ранее проведенном исследовании была подтверждена высокая ретестовая устойчивость диагностируемых показателей $(R=0.732$, 0.585 и 0.404 соответственно, $p<0.007)$. Проверка конструктной валидности свидетельствует о том, что шкалы в русскоязычном варианте методики тесно связаны (вероятности ошибок находятся в диапазоне от $p=0.033$ до $p=0.0001)$ с показателями общей самоэффективности (шкала Р. Шварцера и М. Ерусалема в адаптации В. Ромека), оценкой надежности своего будущего и настоящего (модификация «Методики измерения ненадежности работы» А. Н. Дёмина), уровнем общей интернальности (УСК Е. Ф. Бажина, Е. А. Голынкина, А. М. Эткинда), субъективным экономическим благополучием (опросник В. А. Хащенко), показателями ожидаемой социальной поддержки (И. Сарасон и др.) и планирования будущего (Е. А. Сомова), готовностью к риску («Личностные факторы принятия решения» Т. В. Корниловой) [10].

Также было установлено, что профессиональная идентичность, барьеры развития, потребность в информации, измеренные в конце обучения, позволяют предсказывать такие характеристики карьеры, как: готовность к межорганизационной мобильности, удовлетворенность выбором профессии, тревога по поводу настоящего и будущего, наличие планов осваивать новую профессию; глубина предсказания - 1 год, вероятности ошибок находятся в диапазоне от $p=0.05$ до $p=0.01$ [19]. Конкретное распределение полученных зависимостей (для показателей профессиональной идентичности и барьеров развития вычислялся коэффициент корреляции Пирсона, для показателя потребности в информации - коэффициент корреляции Спирмена) представлено в таблице 1.

Таким образом, установлена прогностическая валидность методики, распространяющаяся на субъективные характеристики карьеры. Если говорить о поведенческих характеристиках карьеры, то, вероятно, нужно оперировать более длительными интервалами времени. 
Таблица 1.

Связи между показателями МИКС в 1-м опросе и субъективными характеристиками карьеры во 2-м опросе через 1 год $(\mathbf{n}=58)$

Table 1.

The TMCS scores in the 1 st survey and subjective career characteristics in the 2 nd survey after a year $(n=58)$

\begin{tabular}{|c|c|c|c|c|c|}
\hline \multirow[b]{2}{*}{$\begin{array}{c}\text { Шкалы МИКС в 1-м } \\
\text { onpoce } \\
\text { The TMCS scales in } \\
\text { the 1st survey }\end{array}$} & \multicolumn{5}{|c|}{$\begin{array}{c}\text { Субъективные характеристики карьеры во 2-м опросе } \\
\text { Subjective career characteristics in the } 2 \text { nd survey }\end{array}$} \\
\hline & 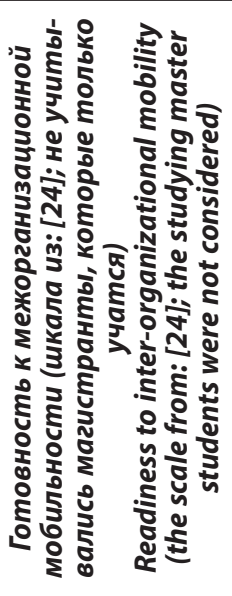 & 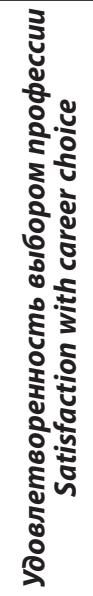 & 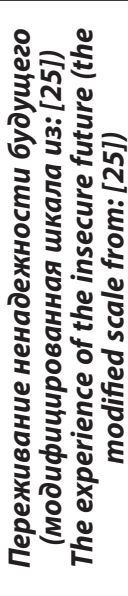 & 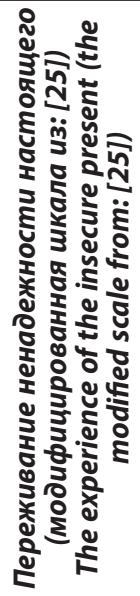 & 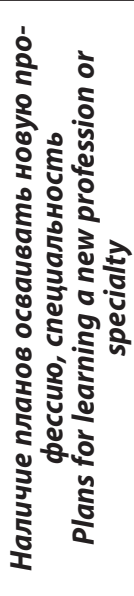 \\
\hline $\begin{array}{l}\text { Профессиональная } \\
\text { идентичность } \\
\text { Vocational Identity }\end{array}$ & $-0.38^{* * *}$ & $0.27^{* *}$ & $-0.35^{* * *}$ & $-0.45^{* * *}$ & 0.15 \\
\hline $\begin{array}{l}\text { Барьеры развития } \\
\text { Barriers }\end{array}$ & 0.12 & -0.16 & $0.28^{* *}$ & $0.20^{*}$ & $-0.29 * *$ \\
\hline $\begin{array}{l}\text { Потребность } \\
\text { в информации } \\
\text { Occupational } \\
\text { Information }\end{array}$ & 0.13 & 0.17 & 0.15 & $0.33^{* * *}$ & $-0.27^{* *}$ \\
\hline
\end{tabular}

Примечание: ${ }^{*}-p<0.1,{ }^{* *}-p<0.05,^{* * *}-p<0.01$.

Note: ${ }^{*}-p<0.1,{ }^{* *}-p<0.05,{ }^{* *}-p<0.01$.

\section{Результаты}

Остановимся на той части адаптации методики, которая связана с ее стандартизацией. Она осуществлялась на выборках студентов последнего (4-го) курса бакалавриата и выпускников бакалавриата, имеющих стаж работы от 2 до 4 лет, т. е. завершающих период полноценной первичной адаптации к рынку труда. 
Выборка студентов ( $n=363$ ) включала обучающихся по разным естественнонаучным и социально-гуманитарным специальностям, средний возраст опрошенных составил 21,3 года, среди них - 41,9\% мужчин и 58,1 \% женщин.

Выборка выпускников бакалавриата $(n=357)$, включала работающих молодых людей, получивших дипломы по аналогичному со студентами кругу специальностей в разных вузах Краснодара. Средний возраст опрошенных составил 24,9 года, среди них - $42 \%$ мужчин и $58 \%$ женщин.

С помощью двухвыборочного критерия Колмогорова - Смирнова было проведено сравнение исходных распределений данных в выборках студентов и работающих выпускников для определения их однородности, т. е. принадлежности к одной и той же генеральной совокупности. В таблице 2 представлены средние и стандартные отклонения, хотя используемый критерий чувствителен и к другим характеристикам распределений [26].

Таблица 2.

Сравнение распределений исходных данных в выборках студентов ( $n=363$ ) и работающих выпускников ( $n=357)$ по шкалам МИКС с помощью критерия однородности Колмогорова - Смирнова

Table 2.

Comparing distribution of the original scores in the samples of students $(n=363)$ and working graduates $(n=357)$ by the TMCS scales by means of Kolmogorov-Smirnov homogeneity criterion

\begin{tabular}{|c|c|c|c|c|c|}
\hline $\begin{array}{c}\text { Наименование } \\
\text { шкал } \\
\text { Scale }\end{array}$ & 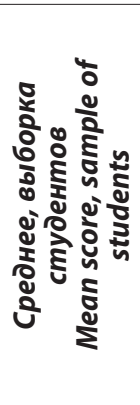 & 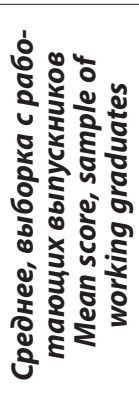 & 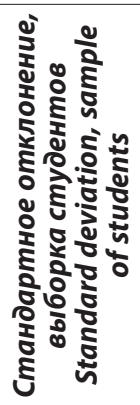 & 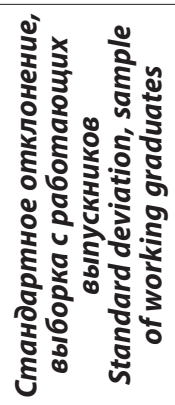 & 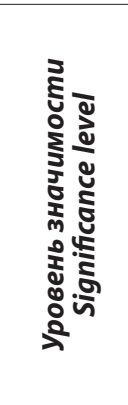 \\
\hline $\begin{array}{c}\text { Профессиональная } \\
\text { идентичность } \\
\text { Vocational Identity }\end{array}$ & 50.23416 & 51.25210 & 9.590093 & 9.986692 & $p>0.1$ \\
\hline $\begin{array}{c}\text { Барьеры развития } \\
\text { Barriers }\end{array}$ & 14.36639 & 14.17647 & 4.381739 & 4.570264 & $p>0.1$ \\
\hline $\begin{array}{c}\text { Потребность } \\
\text { в информации } \\
\text { Occupational } \\
\text { Information }\end{array}$ & 15.53444 & 13.76190 & 3.598772 & 4.258093 & $p<0.001$ \\
\hline
\end{tabular}




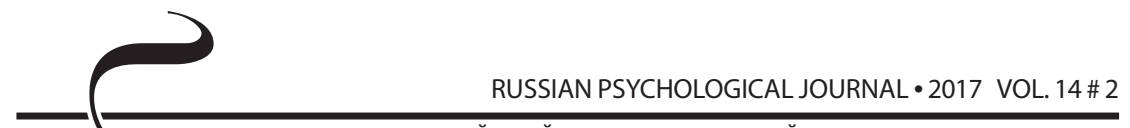

РОССИЙСКИЙ ПСИХОЛОГИЧЕСКИЙ ЖУРНАЛ • 2017 ТОМ 14 № 2

Согласно сделанным расчетам наблюдается достоверное различие между выборками только по одной из трех шкал («Потребность в информации»). Полученный результат более всего согласуется с моделью Д. Сьюпера, согласно которой две обследованные группы попадают в одну стадию карьеры исследовательскую, а различие между ними по параметру потребности в информации объясняется переходом от одной фазы (спецификация выбора) к другой фазе (апробация сделанного карьерного выбора). Для дальнейшей стандартизации методики мы решили объединить выборки по параметрам идентичности и барьеров развития, а третий параметр оценивать для каждой выборки отдельно.

Следующим шагом была проверка нормальности распределений данных, использовался критерий Шапиро - Уилка (W). Если значение критерия W ниже критического значения для принятого уровня значимости, то распределение данных в исследуемой выборке не соответствует нормальному распределению (таблица 3).

Таблица 3.

\section{Проверка нормальности распределения данных по шкалам МИКС}

Table 3.

Checking the normality of data distribution by the TMCS scales

\begin{tabular}{|c|c|c|}
\hline $\begin{array}{c}\text { Наименование шкал } \\
\text { Scale }\end{array}$ & $\begin{array}{c}\text { Значение критерия } \\
\text { Шапupo - Уилка (W) } \\
\text { Shapiro-Wilk test }\end{array}$ & $\begin{array}{l}\text { Уровень значимости } \\
\text { Significance level }\end{array}$ \\
\hline $\begin{array}{c}\text { Профессиональная иден- } \\
\text { тичность, } \mathrm{n}=720 \\
\text { Vocational Identity }\end{array}$ & 0.991 & 0.000 \\
\hline $\begin{array}{c}\text { Барьеры развития, } \mathrm{n}=720 \\
\text { Barriers }\end{array}$ & 0.974 & 0.000 \\
\hline $\begin{array}{c}\text { Потребность в информа- } \\
\text { ции, выборка студентов, } \\
n=363 \\
\text { Occupational Information } \\
\text { (sample of students) }\end{array}$ & 0.919 & 0.000 \\
\hline $\begin{array}{c}\text { Потребность в информа- } \\
\text { ции, выборка работающих } \\
\text { выпускников, } \mathrm{n}=357 \\
\text { Occupational Information } \\
\text { (sample of working } \\
\text { graduates) }\end{array}$ & 0.957 & 0.000 \\
\hline
\end{tabular}

Как видно из таблицы 3, все шкалы достоверно отличаются от нормального распределения, поэтому они были подвергнуты процедуре нелинейной стандартизации. Первый этап нелинейной стандартизации - приведение 
RUSSIAN PSYCHOLOGICAL JOURNAL・2017 VOL. 14 \# 2

шкалы с распределением, отличным от нормального, к равномерному процентильному распределению. Второй этап - преобразование процентильного распределения в нормальное на основании расчетов площади частот значений под нормальной кривой и определение значений z-оценок. Третий этап - перевод z-оценок в стандартную шкалу стенов Кеттелла.

Шкалы профессиональной идентичности и барьеров развития прошли все три этапа стандартизации (таблица 4); для шкалы потребности в информации третий этап стандартизации не осуществлялся, поскольку исходные диапазоны сырых баллов являются небольшими (таблица 5).

Таблица 4.

\section{Значения шкал идентичности и барьеров развития в стенах} Кеттелла на объединенной выборке студентов и работающих выпускников $(\mathbf{n}=\mathbf{7 2 0})$

Table 4.

Vocational Identity and Barriers scales in the united sample of students and working graduates (Cattell's sten scores) $(n=720)$

\begin{tabular}{|c|c|c|c|}
\hline \multicolumn{2}{|c|}{$\begin{array}{c}\text { Профессиональная идентичность } \\
\text { (Min = 18; Max = 72) } \\
\text { Vocational Identity }\end{array}$} & \multicolumn{2}{|c|}{$\begin{array}{c}\text { Барьеры развития } \\
\text { (Min = 7; Max }=28) \\
\text { Barriers }\end{array}$} \\
\hline $\begin{array}{c}\text { Сырые баллы } \\
\text { Raw scores }\end{array}$ & $\begin{array}{c}\text { Стены } \\
\text { Sten scores }\end{array}$ & $\begin{array}{c}\text { Сырые баллы } \\
\text { Raw scores }\end{array}$ & $\begin{array}{c}\text { Стены } \\
\text { Sten scores }\end{array}$ \\
\hline $18-30$ & 1 & $\begin{array}{l}\text { нет данных } \\
\text { No data }\end{array}$ & 1 \\
\hline $31-35$ & 2 & 7 & 2 \\
\hline $36-39$ & 3 & $8-9$ & 3 \\
\hline $40-45$ & 4 & $10-11$ & 4 \\
\hline $46-50$ & 5 & $12-13$ & 5 \\
\hline $51-55$ & 6 & 14-15 & 6 \\
\hline $56-60$ & 7 & $16-18$ & 7 \\
\hline $61-64$ & 8 & 19-20 & 8 \\
\hline $65-67$ & 9 & $21-23$ & 9 \\
\hline $68-72$ & 10 & $24-28$ & 10 \\
\hline
\end{tabular}


Результаты нелинейной стандартизации шкалы потребности в информации на выборке студентов $(n=363)$ и работающих выпускников $(\mathbf{n}=357)$

Table 5.

Nonlinear standardization of the Occupational Information scale in the sample of students $(n=363)$ and working graduates $(n=357)$

\begin{tabular}{|c|c|c|c|c|c|}
\hline \multicolumn{6}{|c|}{$\begin{array}{c}\text { Потребность в информации, студенты }(\text { Min = 5; Max = 20) } \\
\text { Occupational Information, students }\end{array}$} \\
\hline $\begin{array}{c}\text { Сырые } \\
\text { баллы } \\
\text { Raw scores }\end{array}$ & $5-6$ & $7-11$ & $12-19$ & 20 & $\begin{array}{c}\text { нет данных } \\
\text { No data }\end{array}$ \\
\hline $\begin{array}{c}\text { z-показатель } \\
\text { z-score }\end{array}$ & $z \leq-2$ & $-2<z \leq-1$ & $-1<z<1$ & $1 \leq z<2$ & $z \geq 2$ \\
\hline \multicolumn{6}{|c|}{$\begin{array}{c}\text { Потребность в информации, работающие выпускники (Min = 5; Max = 20) } \\
\text { Occupational Information, working graduates }\end{array}$} \\
\hline $\begin{array}{c}\text { Сырые } \\
\text { баллы } \\
\text { Raw scores }\end{array}$ & $\begin{array}{l}\text { нет данных } \\
\text { No data }\end{array}$ & $5-8$ & $9-18$ & 19-20 & $\begin{array}{l}\text { нет данных } \\
\text { No data }\end{array}$ \\
\hline $\begin{array}{c}\text { z-показатель } \\
\text { z-score }\end{array}$ & $z \leq-2$ & $-2<z \leq-1$ & $-1<z<1$ & $1 \leq z<2$ & $z \geq 2$ \\
\hline
\end{tabular}

Как следует из таблицы 5, для студентов выпускного курса удается выделить 4 уровня (низкий, ниже среднего, средний, выше среднего), а для работающих выпускников - 3 уровня (ниже среднего, средний, выше среднего) потребности в информации. Использование уровневых показателей более оправданно при экспресс-диагностике в ситуациях консультирования, а в исследованиях можно применять как уровневый подход, так и сырые баллы.

\section{Текст методики измерения карьерного самоопределения (МИКС)}

В методике дается следующая инструкция: «Оценивая следующие утверждения, выберите тот вариант ответа, который точнее всего отражает Ваше мнение в данный момент и обведите соответствующую цифру». 
Таблица 6.

\section{Содержание пунктов МИКС по шкалам «Карьерная идентичность» и «Барьеры развития»}

Table 6.

The TMCS items by Vocational Identity and Barriers scales

\begin{tabular}{|c|c|c|c|c|c|}
\hline \multicolumn{6}{|c|}{ Если говорить о моей карьере, то: } \\
\hline No $n / n$ & Утверждения & $\begin{array}{l}\text { Да, согла- } \\
\text { сен с этим }\end{array}$ & $\begin{array}{l}\text { Скорее } \\
\text { согласен, } \\
\text { чем не со- } \\
\text { гласен }\end{array}$ & $\begin{array}{c}\text { Скорее } \\
\text { не согла- } \\
\text { сен, чем } \\
\text { согласен }\end{array}$ & $\begin{array}{l}\text { Hem, } \\
\text { не со- } \\
\text { гласен } \\
\text { с этим }\end{array}$ \\
\hline 1 & $\begin{array}{c}\text { Мне необходимо под- } \\
\text { тверждение того, что } \\
\text { я сделал правильный } \\
\text { выбор профессии }\end{array}$ & 1 & 2 & 3 & 4 \\
\hline 2 & $\begin{array}{c}\text { Меня беспокоит, что } \\
\text { мои нынешние инте- } \\
\text { ресы с годами могут } \\
\text { измениться }\end{array}$ & 1 & 2 & 3 & 4 \\
\hline 3 & $\begin{array}{c}\text { Я не знаю, какие виды } \\
\text { деятельности я мог бы } \\
\text { хорошо выполнять }\end{array}$ & 1 & 2 & 3 & 4 \\
\hline 4 & $\begin{array}{c}\text { Я не знаю своих основ- } \\
\text { ных сильных и слабых } \\
\text { сторон }\end{array}$ & 1 & 2 & 3 & 4 \\
\hline 5 & $\begin{array}{l}\text { Работы, которые я могу } \\
\text { выполнять, вряд ли обе- } \\
\text { спечат меня средствами } \\
\text { для того образа жизни, } \\
\text { который мне нравится }\end{array}$ & 1 & 2 & 3 & 4 \\
\hline 6 & $\begin{array}{c}\text { Если бы мне пришлось } \\
\text { выбирать профессию } \\
\text { сейчас, боюсь, что я сде- } \\
\text { лал бы неудачный выбор }\end{array}$ & 1 & 2 & 3 & 4 \\
\hline 7 & $\begin{array}{c}\text { Я чувствую растерян- } \\
\text { ность, когда думаю над } \\
\text { тем, как строить буду- } \\
\text { щую карьеру }\end{array}$ & 1 & 2 & 3 & 4 \\
\hline 8 & $\begin{array}{c}\text { Определиться со сво- } \\
\text { ей карьерой - давняя } \\
\text { и сложная проблема для } \\
\text { меня }\end{array}$ & 1 & 2 & 3 & 4 \\
\hline 9 & $\begin{array}{c}\text { В целом проблема при- } \\
\text { нятия решения по пово- } \\
\text { ду карьеры ставит меня } \\
\text { в тупик }\end{array}$ & 1 & 2 & 3 & 4 \\
\hline
\end{tabular}




\begin{tabular}{|c|c|c|c|c|c|}
\hline \multicolumn{6}{|c|}{ Если говорить о моей карьере, то: } \\
\hline № $n / n$ & Утверждения & $\begin{array}{l}\text { Да, согла- } \\
\text { сен с этим }\end{array}$ & $\begin{array}{l}\text { Скорее } \\
\text { согласен, } \\
\text { чем не со- } \\
\text { гласен }\end{array}$ & $\begin{array}{l}\text { Скорее } \\
\text { не согла- } \\
\text { сен, чем } \\
\text { согласен }\end{array}$ & $\begin{array}{l}\text { Hem, } \\
\text { не со- } \\
\text { гласен } \\
\text { с этим }\end{array}$ \\
\hline 10 & $\begin{array}{c}\text { Я не уверен в том, что } \\
\text { мой нынешний выбор } \\
\text { профессии - это точно } \\
\text { «мое» }\end{array}$ & 1 & 2 & 3 & 4 \\
\hline 11 & $\begin{array}{c}\text { Я недостаточно знаю } \\
\text { о том, что делают работ- } \\
\text { ники в моей и близких } \\
\text { ей специальностях }\end{array}$ & 1 & 2 & 3 & 4 \\
\hline 12 & $\begin{array}{c}\text { По-моему, нет работы, } \\
\text { которая однозначно } \\
\text { подходила бы мне }\end{array}$ & 1 & 2 & 3 & 4 \\
\hline 13 & $\begin{array}{c}\text { Я не знаю, какой рабо- } \\
\text { той я мог бы заниматься } \\
\text { с удовольствием }\end{array}$ & 1 & 2 & 3 & 4 \\
\hline 14 & $\begin{array}{c}\text { Я бы хотел расширить } \\
\text { число профессий, } \\
\text { которые можно рас- } \\
\text { сматривать в качестве } \\
\text { вариантов дальнейшей } \\
\text { карьеры }\end{array}$ & 1 & 2 & 3 & 4 \\
\hline 15 & $\begin{array}{c}\text { Мои оценки собствен- } \\
\text { ных способностей силь- } \\
\text { но меняются из года } \\
\text { в год }\end{array}$ & 1 & 2 & 3 & 4 \\
\hline 16 & $\begin{array}{c}\text { Я не уверен в себе } \\
\text { во многих областях } \\
\text { жизни }\end{array}$ & 1 & 2 & 3 & 4 \\
\hline 17 & $\begin{array}{c}\text { Когда я принимал ре- } \\
\text { шение о выборе про- } \\
\text { фессии, я размышлял } \\
\text { об этом менее одного } \\
\text { года }\end{array}$ & 1 & 2 & 3 & 4 \\
\hline 18 & $\begin{array}{c}\text { Я не понимаю, как неко- } \\
\text { торые люди могут быть } \\
\text { такими уверенными } \\
\text { относительно того, чем } \\
\text { они хотят заниматься }\end{array}$ & 1 & 2 & 3 & 4 \\
\hline 19 & $\begin{array}{l}\text { Я не уверен в своей спо- } \\
\text { собности получить не- } \\
\text { обходимую для дальней- } \\
\text { шей работы подготовку }\end{array}$ & 1 & 2 & 3 & 4 \\
\hline
\end{tabular}




\begin{tabular}{|c|c|c|c|c|c|}
\hline \multicolumn{6}{|c|}{ Если говорить о моей карьере, то: } \\
\hline № $n / n$ & Утверждения & $\begin{array}{l}\text { Да, согла- } \\
\text { сен с этим }\end{array}$ & $\begin{array}{l}\text { Скорее } \\
\text { согласен, } \\
\text { чем не со- } \\
\text { гласен }\end{array}$ & $\begin{array}{c}\text { Скорее } \\
\text { не согла- } \\
\text { сен, чем } \\
\text { согласен }\end{array}$ & $\begin{array}{l}\text { Hem, } \\
\text { не со- } \\
\text { гласен } \\
\text { с этим }\end{array}$ \\
\hline 20 & $\begin{array}{c}\text { У меня недостаточно } \\
\text { материальных средств, } \\
\text { чтобы начать (или про- } \\
\text { должить) ту карьеру, } \\
\text { которая мне больше } \\
\text { всего нравится }\end{array}$ & 1 & 2 & 3 & 4 \\
\hline 21 & $\begin{array}{c}\text { Мне не хватает способ- } \\
\text { ностей, чтобы зани- } \\
\text { маться той профессией, } \\
\text { которую я выбрал }\end{array}$ & 1 & 2 & 3 & 4 \\
\hline 22 & $\begin{array}{c}\text { Человек, имеющий боль- } \\
\text { шое значение в моей } \\
\text { жизни, не одобряет } \\
\text { мой профессиональный } \\
\text { выбор }\end{array}$ & 1 & 2 & 3 & 4 \\
\hline 23 & $\begin{array}{c}\text { Мне не хватает на- } \\
\text { стойчивости для пре- } \\
\text { одоления трудностей } \\
\text { в карьере }\end{array}$ & 1 & 2 & 3 & 4 \\
\hline 24 & $\begin{array}{c}\text { У меня недостаточно со- } \\
\text { циальных связей и зна- } \\
\text { комств для успешной } \\
\text { карьеры }\end{array}$ & 1 & 2 & 3 & 4 \\
\hline 25 & $\begin{array}{c}\text { Сложившаяся экономи- } \\
\text { ческая (социальная) си- } \\
\text { туация в стране или ре- } \\
\text { гионе не позволит мне } \\
\text { реализовать ту карьеру, } \\
\text { которая мне нравится }\end{array}$ & 1 & 2 & 3 & 4 \\
\hline
\end{tabular}

Для подсчета сырых баллов по шкале «Карьерная идентичность» необходимо суммировать пункты 1-18.

Для подсчета сырых баллов по шкале «Барьеры развития» необходимо суммировать пункты 19-25, а полученную сумму вычесть из 35. 
Таблица 7.

\section{Содержание пунктов МИКС по шкале «Потребность в информации»}

The TMCS items by Occupational Information scale

Table 7.

\begin{tabular}{|c|c|c|c|c|c|}
\hline \multicolumn{6}{|c|}{ Мне нужна следующая информация: } \\
\hline $\begin{array}{l}\text { No } \\
n / n\end{array}$ & $\begin{array}{l}\text { Содержание } \\
\text { информации }\end{array}$ & $\begin{array}{l}\text { Да, согла- } \\
\text { сен с этим }\end{array}$ & $\begin{array}{l}\text { Скорее со- } \\
\text { гласен, чем } \\
\text { не согласен }\end{array}$ & $\begin{array}{c}\text { Скорее не со- } \\
\text { гласен, чем } \\
\text { согласен }\end{array}$ & $\begin{array}{l}\text { Hет, не со- } \\
\text { гласен } \\
\text { с этим }\end{array}$ \\
\hline 26 & $\begin{array}{l}\text { Как найти рабо- } \\
\text { ту в выбранной } \\
\text { специальности }\end{array}$ & 1 & 2 & 3 & 4 \\
\hline 27 & $\begin{array}{c}\text { Какие требования } \\
\text { предъявляют раз- } \\
\text { личные профессии } \\
\text { к людям }\end{array}$ & 1 & 2 & 3 & 4 \\
\hline 28 & $\begin{array}{c}\text { О возмож- } \\
\text { ных вариантах } \\
\text { трудоустройства }\end{array}$ & 1 & 2 & 3 & 4 \\
\hline 29 & $\begin{array}{c}\text { Как получить до- } \\
\text { полнительную под- } \\
\text { готовку (опыт, обу- } \\
\text { чение) в выбранной } \\
\text { профессии }\end{array}$ & 1 & 2 & 3 & 4 \\
\hline 30 & $\begin{array}{c}\text { Какие профессии } \\
\text { востребованы } \\
\text { на рынке труда }\end{array}$ & 1 & 2 & 3 & 4 \\
\hline
\end{tabular}

Для подсчета сырых баллов по шкале «Потребность в информации» необходимо суммировать пункты 26-30, а полученную сумму вычесть из 25.

\section{Обсуждение результатов}

Таким образом, завершена русскоязычная адаптация методики «Му Vocational Situation» (русскоязычный вариант - «Методика измерения карьерного самоопределения») на российских выборках студентов и выпускников бакалавриата, включая ее стандартизацию.

Методика измерения карьерного самоопределения достаточно проста и компактна. Она может найти применение в научных исследованиях, в консультативной практике, при валидизации новых психодиагностических инструментов. Стандартизация шкалы профессиональной идентичности позволяет включать ее в мониторинговые и сравнительные исследования, в том числе используя с другими стандартизованными тестами для их совместной интерпретации. 
Основной объект применения методики - студенты и выпускники вузов и других профессиональных учебных заведений. Безусловно, представляет интерес применение данной методики к старшеклассникам и абитуриентам. Важно накопление опыта использования данной методики в разных регионах России для ее последующей рестандартизации.

\section{Литература}

1. Дёмин А. Н. Личность в кризисе занятости: стратегии и механизмы преодоления кризиса: дисс. ... доктора психол. наук. - Краснодар, 2005. - 407 с.

2. Aquilanti T. M., Leroux J. An integrated model of outplacement counseling // Journal of Employment Counseling. - 1999. - Vol. 36, № 4. - P. 177-192. DOI: 10.1002/j.2161-1920.1999.tb01020.x

3. Super D. E. A life-span, life-space approach to career development. Career Choice and Development / D. Brown, L. Brooks (eds.). - San Francisco : Jossey-Bass, 1990. - 2nd ed. - P. 167-261.

4. Super D. E., Osborne W. L., Walsh D. J., Brown S. D., Niles S. G. Developmental career assessment and counseling: The C-DAC model // Journal of Counseling \& Development. - 1992. - Vol. 71, № 1. - P. 74-80. - DOI: /10.1002/ j.1556-6676.1992.tb02175.x

5. Fugate M., Kinicki A. J., Ashford B. E. Employability: A psycho-social construct, its dimensions, and applications // Journal of Vocational Behavior. - 2004. Vol. 65, № 1. - P. 14-38. - DOI: 10.1016/j.jvb.2003.10.005

6. Defillippi R. J., Arthur M. B. The boundaryless career: A competency-based perspective // Journal of Organizational Behavior. - 1994. - Vol. 15. - P. 307 324. - DOI: 10.1002/job.4030150403

7. Inkson K., Arthur M. B. How to be a successful career capitalist // Organizational Dynamics. - 2001. - Vol. 30. - P. 48-61. - DOI: 10.1016/s00902616(01)00040-7

8. Gottfredson G. D. John L. Holland's contributions to vocational psychology: a review and evaluation // Journal of Vocational Behavior. - 1999. - Vol. 55, № 1. - P. 15-40. - DOI: 10.1006/jvbe.1999.1695

9. Holland J. L., Gottfredson D. C., \& Power P. G. Some diagnostic scales for research in decision making and personality: Identity, information, and barriers // Journal of Personality and Social Psychology. - 1980. - Vol. 39. P. 1191-1200. - DOI: 10.1037/h0077731

10. Дёмин A. Н., Седых А. Б. Адаптация методики для изучения карьерного самоопределения личности // Человек. Сообщество. Управление. 2013. - № 4. - C. 6-16.

11. Nauta M. M. The Development, Evolution, and Status of Holland's Theory of Vocational Personalities: Reflections and Future Directions for Counseling 
Psychology // Journal of Counseling Psychology. - 2010. - Vol. 15, № 1. P. 11-22. - DOI: 10.1037/a0018213

12. Азбель А. А. Особенности формирования статусов профессиональной идентичности старшеклассников : дисс. ... канд. психол. наук. - СПб., 2004. - 219 c.

13. Шнейдер Л. Б. Личностная, гендерная и профессиональная идентичность: теория и методы диагностики. - М. : Изд-во МПСИ, 2007. - 128 с.

14. Джанерьян С. Т., Берлова Т. Н. Личностные детерминанты стратегий учебно-профессиональной карьеры работающих студентов // Казанская наука. - 2014. - № 5. - С. 174-177.

15. Ермолаева Е. П. Профессиональная идентичность и маргинализм: концепция и реальность (статья первая) // Психологический журнал. 2001. - Т. 22, № 4. - С. 51-59.

16. Толочек В. А. О возможности новых подходов к профессиональному становлению субъекта // Психология. Экономика. Право. - 2013. № 1. - С. 6-15.

17. Толочек В. А., Журавлева Н. И. Динамика актуализации психологических ресурсов субъектом на протяжении профессиональной карьеры // Психологический журнал. - 2015. - Т. 36, № 1. - С. 91-107.

18. Reardon R. C., Lenz J. G. Holland's Theory and Career Assesment // Journal of Vocational Behavior. - 1999. - Vol. 55. - P. 102-113. - DOI: 10.1006/ jvbe.1999.1700

19. Дёмин А. Н., Седых А. Б. Прогнозирование компонентов карьеры на основе «Методики измерения карьерного самоопределения» // XII Международная научно-практическая конференция «Психология личностнопрофессионального развития: современные вызовы и риски» / под ред. Л. М. Митиной. - М. : Перо, 2016. - С. 295-297. - URL: http://www.pirao.ru/ images/news/2016/08/XII-Vyzovy-i-Riski.pdf (дата обращения 23.05.2017).

20. Holland J. L., Johnston J. A., Asama N. F. The Vocational Identity Scale: A diagnostic and treatment tool // Journal of Career Assessment. - 1993. - Vol. 1, № 1. - P. 1-11. - DOI: 10.1177/106907279300100102

21. Santos P. J. Goal instability, self-esteem, and vocational identity of high school Portuguese students // Análise Psicológica. - 2003. - № 2. - P. 229-238. DOI: $10.14417 / a p .112$

22. Smitina $A$. The link between vocational identity, study choice motivation and satisfaction with studies // Procedia - Social and Behavioral Sciences. 2010. - Vol. 5. - P. 1140-1145. - DOI: 10.1016/j.sbspro.2010.07.250

23. Tosado L. A. An Exploratory Study of a Measure of Vocational Identity for Spanish-speaking Persons : diss.... for the degree of Doctor of Philosophy. University of Maryland, College Park, 2012. - 94 p. 
24. Walsh J. P., Ashford S. J., Hill T. E. Feedback obstruction: The influence of the information environment on employee turnover intentions // Human Relations. - 1985. - Vol. 38. - P. 23-46. - DOI: 10.1177/001872678503800102

25. Дёмин А. Н., Петрова И. А. Психологические эффекты угрозы потери работы // Психологический журнал. - 2010. - Т. 31. - № 6. - С. 38-49.

26. Боровиков В. П. STATISTICA: искусство анализа данных на компьютере. СПб.: ПИТЕР, 2003. - 2-е изд. - 688 с.

\section{References}

1. Diomin A. N. Lichnost'v krizise zanyatosti: strategii i mekhanizmy preodoleniya krizisa [Personality in the employment crisis: Strategies and mechanisms for overcoming the crisis]. Diss. Dr. Sci. (Psych.). Krasnodar, 2005. 407 p.

2. Aquilanti T. M., Leroux J. An integrated model of outplacement counseling. Journal of Employment Counseling, 1999, V. 36, no. 4, pp. 177-192. DOI: 10.1002/j.2161-1920.1999.tb01020.x

3. Super D. E. A life-span, life-space approach to career development. Career Choice and Development. San Francisco: Jossey-Bass, 1990, pp. 167-261.

4. Super D. E., OsborneW. L., Walsh D. J., Brown S. D., Niles S. G. Developmental career assessment and counseling:The C-DAC model. Journal of Counseling \& Development, 1992, V. 71, no. 1, pp. 74-80. DOI:/10.1002/j.1556-6676.1992.tb02175.x

5. Fugate M., Kinicki A. J., Ashford B. E. Employability: A psycho-social construct, its dimensions, and applications. Journal of Vocational Behavior, 2004, V. 65, no. 1, pp. 14-38. DOI: 10.1016/j.jvb.2003.10.005

6. Defillippi R. J., Arthur M. B. The boundaryless career: A competency-based perspective. Journal of Organizational Behavior, 1994, V. 15, pp. 307-324. DOI: $10.1002 /$ job.4030150403

7. Inkson K., Arthur M. B. How to be a successful career capitalist. Organizational Dynamics, 2001, V. 30, pp. 48-61. DOI: 10.1016/s0090-2616(01)00040-7

8. Gottfredson G. D. John L. Holland's contributions to vocational psychology: a review and evaluation. Journal of Vocational Behavior, 1999, V. 55, no. 1, pp. 15-40. DOI: 10.1006/jvbe.1999.1695

9. Holland J. L., Gottfredson D. C., \& Power P. G. Some diagnostic scales for research in decision making and personality: Identity, information, and barriers. Journal of Personality and Social Psychology, 1980, V. 39, pp. 1191-1200. DOI: 10.1037/h0077731

10. Diomin A. N., Sedykh A. B. Modification of the technique for studying career self-determination. Chelovek. Soobshhestvo. Upravlenie - Human. Community. Management, 2013, no. 4, pp. 6-16 (in Russian).

11. Nauta M. M. The development, evolution, and status of Holland's theory of vocational personalities: reflections and future directions for counseling 
psychology. Journal of Counseling Psychology, 2010, V. 15, no. 1, pp. 11-22. DOI: $10.1037 / \mathrm{a} 0018213$

12. Azbel' A. A. Osobennosti formirovanija statusov professional'noj identichnosti starsheklassnikov [Features of the formation of professional identity statuses in senior pupils]. Diss. Cand. Sci. (Psych.). St. Petersburg, 2004. 219 p.

13. Shnejder L. B. Lichnostnaja, gendernaja i professional'naja identichnost': teorija i metody diagnostiki [Personal, gender and professional identity: Theory and methods of diagnostics]. Moscow, MPSI Publ., 2007. 128 p. (in Russian).

14. Dzhaner'jan S. T., Berlova T. N. Personal determinants of the strategies of educational and professional career in working students. Kazanskaja nauka - Kazan Science, 2014, no. 5, pp. 174-177 (in Russian).

15. Ermolaeva E. P. Professional identity and marginalism: A concept and reality (Part 1). Psihologicheskij zhurnal - Psychological Journal, 2001, V. 22, no. 4, pp. 51-59 (in Russian).

16. Tolochek V. A. On new approaches to the professional development of the subject. Psihologija. Jekonomika. Pravo - Psychology. Economics. Law, 2013, no. 1, pp. 6-15 (in Russian).

17. Tolochek V. A., Zhuravleva N. I. The dynamics of the subject's actualization of psychological resources in professional career. Psihologicheskij zhurnal Psychological Journal, 2015, V. 36, no. 1, pp. 91-107 (in Russian).

18. Reardon R. C., Lenz J. G. Holland's theory and career assesment. Journal of Vocational Behavior, 1999, V. 55, pp. 102-113. DOI: 10.1006/jvbe.1999.1700

19. Diomin A. N., Sedykh A. B. Prognozirovanie komponentov kar'ery na osnove «Metodiki izmerenija kar'ernogo samoopredelenija» [Forecasting the components of career by the "Technique for measuring career self-determination"]. XII Mezhdunarodnaja nauchno-prakticheskaja konferencija "Psihologija lichnostno-professional'nogo razvitija: sovremennye vyzovy i riski" [Proc. the 12th International Theoretical and Practical Conference "Psychology of personal and professional development: challenges and risks"]. Moscow, Pero Publ., 2016, pp. 295-297. Available at: http://www.pirao.EN/images/ news/2016/08/XII-Vyzovy-i-Riski.pdf (Accessed 23 May 2017).

20. Holland J. L., Johnston J. A., Asama N. F. The vocational identity scale: A diagnostic and treatment tool. Journal of Career Assessment, 1993, V. 1, no. 1, pp. 1-11. DOI: 10.1177/106907279300100102

21. Santos P. J. Goal instability, self-esteem, and vocational identity of high school Portuguese students. Análise Psicológica, 2003, no. 2, pp. 229-238. DOI: $10.14417 / a p .112$

22. Smitina A. The link between vocational identity, study choice motivation and satisfaction with studies. Procedia - Social and Behavioral Sciences, 2010, V. 5, pp. 1140-1145. DOI: 10.1016/j.sbspro.2010.07.250 
RUSSIAN PSYCHOLOGICAL JOURNAL • 2017 VOL. 14\# 2

23. Tosado L. A. An exploratory study of a measure of vocational identity for Spanish-speaking persons. Diss. Dr. of Philosophy. University of Maryland, College Park, 2012. $94 \mathrm{p}$.

24. Walsh J. P., Ashford S. J., Hill T. E. Feedback obstruction: The influence of the information environment on employee turnover intentions. Human Relations, 1985, V. 38, pp. 23-46. DOI: 10.1177/001872678503800102

25. Diomin A. N., Petrova I. A. Psychological effects of the threat of job loss. Psihologicheskij zhurnal - Psychological Journal, 2010, V. 31, no. 6, pp. 38-49.

26. Borovikov V.P.STATISTICA: iskusstvo analiza danny n n komp'jutere [STATISTICA: the art of computer data analysis]. St. Petersburg, Piter Publ., 2003. 688 p. 